\title{
A PCR-RFLP Analysis of the Szp Gene in Streptococcus zooepidemicus Isolates from Mares with Metritis in Japan
}

\author{
Youichi KUROIWA ${ }^{1}$, Toru ANZAI ${ }^{2 *}$, Tohru HIGUCHI ${ }^{\mathbf{3}}$ and Takuo SAWADA ${ }^{\mathbf{1}}$ \\ ${ }^{1}$ Department of Veterinary Microbiology, Faculty of Veterinary Medicine, Nippon Veterinary and Life Science \\ University, Musashino, Tokyo 180-8602, ${ }^{2}$ Epizootic Research Center, Equine Research Institute, Japan Racing \\ Association, 1400-4 Shiba, Shimotsuke-shi, Tochigi 329-0412, ${ }^{3}$ Mitsuishi Animal Clinic Center, Agriculture \\ Mutual Aid Association of Hidaka District, 200 Mitsuishi-higashihôrai, Shin-hidaka-chô, Hokkaido 059-3105, \\ Japan
}

Two hundred and four strains of $S$. zooepidemicus were isolated from the genital sites of mares diagnosed with metritis. The isolates were differentiated by PCR-RFLP analysis of the J. Equine Sci. szp gene. The 30 kinds of restriction fragment profiles were defined by 4 to 6 sizes of DNA fragments ranging from approximately 65 to $390 \mathrm{bp}$. Although 16 of the 30 PCR-RFLP Vol. 17, No. 4 profiles consisted of 149 isolates, $73 \%$ were identical to the szp of the organisms from horses with respiratory disease. The remaining 14 consisted of 55 isolates of which $27 \%$ were newly found. Ten genital swabs which were positive for isolation of the organisms were used to investigate whether the 5 clones of the organisms from a single sample were genetically identical to each other or not. Results showed each of 5 clones to be indistinguishable, expect for 1 clone from a single swab. In conclusion, the usefulness of PCR-RFLP analysis in discriminating between strains was demonstrated on genital isolates in the same way as for respiratory isolates, suggesting that the major isolates were szp genotypes that are present at both genital and respiratory sites, even though it was suspected that some genotypes specifically infect the genital site or the respiratory site.

Key words: genotyping, horse, PCR-RFLP, Streptococcus zooepidemicus, SzP

Streptococcus zooepidemicus (S. equi subsp. zooepidemicus) is a commensal bacterium of the pharyngeal tonsils and nasopharyngeal mucosa of horses [1,2]. However, opportunistic infections by this organism of the respiratory, intestinal and reproductive tracts have been reported $[1-3,6]$. This bacterium can be a causative agent of purulent rhinitis, bronchitis or pneumonia in horses under stress caused by transportation or virus infections. S. zooepidemicus may also be an important cause of inflammation of the uterus or the uterine cervix, since the organism is isolated from mares with suspected metritis at high percentages in cases in the field; however, it is only rarely isolated from the uteri of clinically normal mares $[4,5$, this paper $]$.

This article was accepted July 25, 2006

*Corresponding author. e-mail: anzai@epizoo.equinst.go.jp
SzP, a surface M-like protein of $S$. zooepidemicus strains has shown diversity in the sequence and the size of its gene $[7,8,10]$. In a previous study, we compared the $\mathrm{SzP}$ protein and the genes from healthy horses with those from foals and donkeys with pneumonia [2]. The results showed the tonsils of every healthy horse to be colonized by a range of $\mathrm{SzP}$ phenotypes similar to those in foals or donkeys with pneumonia, even though numerous isolates from animals with pneumonia had a single SzP phenotype, indicating infection by a single strain or clone.

In another study, we adopted a PCR-RFLP analytical technique for szp typing of $S$. zooepidemicus as a convenient tool for molecular epidemiology [1]. Its precise differentiation has made it possible to demonstrate that a certain $s z p$ genotype of the organism can transfer from the upper respiratory tract to the lower in yearling horses during long-distance transportation. The results of the second study 
revealed that analysis of $s z p$ by means of PCR-RFLP is practical for molecular typing of $S$. zooepidemicus strains in the study of respiratory tract diseases in horses; and that a single strain of $S$. zooepidemicus can migrate from the pharyngeal tonsils onto the trachea at a high rate in horses undergoing long-distance transportation.

The purpose of the study presented here was to analyze genetically the genital isolates of $S$. zooepidemicus from mares diagnosed with metritis using the PCRRFLP method. The results obtained were compared with those in the respiratory isolates mentioned above.

\section{Materials and Methods}

\section{Bacteria}

A total of 204 S. zooepidemicus isolates were obtained from the uterine cervix of thoroughbred mares diagnosed with metritis from the Hidaka racehorse breeding district of Japan from 1982 to 2004. The numbers of the isolates were shown in Table 1 of the Results section. Isolation and growth of bacteria was performed using Colombia blood agar (Becton Dickinson Microbiology Systems, Sparks, MD, USA) plate with horse blood. The API 20 STREP (bioMérieux, Marcy-l'Etoile, France) was used to identify the isolates containing $S$. zooepidemicus. All isolates were stored at $-80^{\circ} \mathrm{C}$ before use. In this study, five $S$. zooepidemicus colonies isolated on blood agar plates inoculated with individual swabs of the uterine cervix were used for the investigation of whether the organisms from a single sample were genetically identical or not.

\section{PCR-RFLP analysis}

The PCR-RFLP analytical procedure was carried out in the same manner as described previously [1]. Briefly, bacterial genome DNA was extracted using the InstaGene Matrix (Bio-Rad Laboratories, CA, USA), and used for the PCR amplification of $s z p$. The PCR mixture contained $1 \mu l$ of genome DNA, $200 \mathrm{pM}$ each of oligonucleotide primers, N, 5'ACAAAAGGGGAATAAAATGGC and NCR4, 5'TTTACCACTGGGGTATAAGGCTT, $200 \mu \mathrm{M}$ each of dNTPs, 2.5 units of Z-Taq DNA polymerase (Takara Shuzô Biomedical Group, Shiga, Japan), in a total volume of $100 \mu l$ of PCR buffer $(100 \mathrm{mM} \mathrm{KCl}, 20 \mathrm{mM}$ Tris $\left.\mathrm{pH} 8.0,3 \mathrm{mM} \mathrm{MgCl}_{2}\right)$. PCR was performed as follows: initial denaturation for $3 \mathrm{~min}$ at $98^{\circ} \mathrm{C}$ followed by 30 cycles of annealing at $55^{\circ} \mathrm{C}$ for $5 \mathrm{sec}$, elongation at $72^{\circ} \mathrm{C}$ for $10 \mathrm{sec}$ and denaturation at $98^{\circ} \mathrm{C}$ for $1 \mathrm{sec}$. After the final cycle, the samples were incubated for 3 min at $72^{\circ} \mathrm{C}$. The PCR products were purified using MicroSpin S-400 HR columns (Amersham Pharmacia Biotech, Buckinghamshire, England), and then digested with the restriction endonuclease $D d e$ I. DNA fragments were electrophoresed on $3.5 \%$ agarose gels. The sizes of the DNA fragments were estimated by comparison with DNA size markers.

\section{Results}

Four, 5 or 6 sizes of DNA fragments ranging from approximately 65 to 390 bp were derived from the PCR products of all of the $204 \mathrm{~S}$. zooepidemicus isolates by digestion with the restriction enzyme $D d e \mathrm{I}$. Thirty different profiles were defined according to the number and sizes of the fragments. Fourteen kinds of these 30 profiles were identical to those appearing in the respiratory isolates from horses. These profiles were present in 149 of the 204 isolates $(73 \%)$. Table 1 summarizes the 34 kinds of PCR-RFLP profiles designated as "sz $p$ genotypes". The sizes of the definitive DNA fragments of the 14 genotypes detected in the organisms from both genital and respiratory sites, and the remaining 20 genotypes, are shown in the second column of the Table. Of the non-identical 20 genotypes, 4 were detected in the respiratory organs (genotypes 2, 4, 13 and 18), and 16 were in the genitals (genotypes 19 to 34 ).

Table 2 shows the $s z p$ genotypes determined for 5 clones of $S$. zooepidemicus from each of 10 genital swabs of 10 mares also diagnosed with metritis. The 5 clones were obtained from 5 independent colonies formed on an agar plate in the initial isolation. Although all the clones had identical PCR-RFLP profiles in the 9 swabs, 1 clone was different from the other 4 in swab no. 6 .

\section{Discussion}

In a previous study, we developed a PCR-RFLP analytical method for the genetic typing of $S$. zooepidemicus [1]. PCR amplification of $s z p$ followed by digestion with the restriction enzyme $D d e$ I enabled the precise characterization of $S$. zooepidemicus isolates from respiratory diseases in horses. In this study, 8 of $34 s z p$ genotypes consisted of only 1 isolate of the organisms, 
Table 1. Streptococcus zooepidemicus szp genotypes of 204 isolates from the genitals and 37 from the respiratory organs of horses

\begin{tabular}{|c|c|c|c|c|c|c|c|c|c|}
\hline \multirow{3}{*}{$\begin{array}{l}S z p \\
\text { genotypes }\end{array}$} & \multirow{3}{*}{$\begin{array}{c}\text { PCR-RFLP } \\
\text { profiles (bp*) }\end{array}$} & \multicolumn{8}{|c|}{ No. of isolates } \\
\hline & & \multirow[b]{2}{*}{ 1982-4 } & \multicolumn{5}{|c|}{ Genital tract } & \multirow{2}{*}{$\begin{array}{c}\text { Respiratory } \\
\text { tract }\end{array}$} & \multirow[b]{2}{*}{ Tota } \\
\hline & & & 1985 & $1986-8$ & $1991-2$ & 2004 & Subtotal & & \\
\hline 1 & $210,190,130,120,100,90$ & 2 & 4 & 2 & 1 & 13 & 22 & 7 & 29 \\
\hline 2 & $290,190,180,130,90$ & 0 & 0 & 0 & 0 & 0 & 0 & 2 & 2 \\
\hline 3 & $250,210,190,130,100$ & 3 & 3 & 0 & 1 & 13 & 20 & 1 & 30 \\
\hline 4 & $390,210,130,100$ & 0 & 0 & 0 & 0 & 0 & 0 & 9 & 9 \\
\hline 5 & $250,190,150,135,130$ & 2 & 2 & 1 & 2 & 8 & 15 & 1 & 16 \\
\hline 6 & $295,290,130,100$ & 0 & 1 & 0 & 0 & 1 & 2 & 1 & 3 \\
\hline 7 & $350,290,130,120$ & 8 & 6 & 4 & 3 & 13 & 34 & 1 & 35 \\
\hline 8 & $360,350,130,100$ & 0 & 2 & 0 & 1 & 2 & 5 & 2 & 7 \\
\hline 9 & $350,290,130,100,65$ & 0 & 0 & 0 & 1 & 1 & 2 & 2 & 4 \\
\hline 10 & $295,290,130,100,65$ & 0 & 3 & 2 & 2 & 10 & 17 & 1 & 18 \\
\hline 11 & $350,190,130,120,90$ & 2 & 2 & 0 & 1 & 6 & 11 & 2 & 13 \\
\hline 12 & $290,190,180,130,100$ & 0 & 0 & 0 & 0 & 2 & 2 & 2 & 4 \\
\hline 13 & $190,135,125,90,85$ & 0 & 0 & 0 & 0 & 0 & 0 & 1 & 1 \\
\hline 14 & $210,195,190,130,100$ & 1 & 0 & 0 & 0 & 2 & 3 & 1 & 4 \\
\hline 15 & $350,190,135,130,90$ & 0 & 0 & 0 & 5 & 4 & 9 & 1 & 10 \\
\hline 16 & $290,190,150,130$ & 1 & 0 & 0 & 1 & 0 & 2 & 1 & 3 \\
\hline 17 & $190,135,130,90,85$ & 0 & 0 & 0 & 1 & 4 & 5 & 1 & 6 \\
\hline 18 & $350,290,130,100$ & 0 & 0 & 0 & 0 & 0 & 0 & 1 & 1 \\
\hline 19 & $250,190,150,130,90$ & 0 & 3 & 1 & 2 & 12 & 18 & 0 & 18 \\
\hline 20 & $250,195,190,130$ & 2 & 0 & 5 & 0 & 1 & 8 & 0 & 8 \\
\hline 21 & $290,210,180,130,100$ & 0 & 3 & 0 & 0 & 1 & 4 & 0 & 4 \\
\hline 22 & $350,290,135,130$ & 1 & 0 & 0 & 0 & 3 & 4 & 0 & 4 \\
\hline 23 & $350,195,190,130$ & 0 & 0 & 0 & 0 & 3 & 3 & 0 & 3 \\
\hline 24 & $350,190,150,130,100$ & 0 & 0 & 0 & 0 & 3 & 3 & 0 & 3 \\
\hline 25 & $290,210,130,120,100$ & 0 & 0 & 0 & 0 & 3 & 3 & 0 & 3 \\
\hline 26 & $320,190,150,130,100$ & 1 & 0 & 0 & 1 & 0 & 2 & 0 & 2 \\
\hline 27 & $350,250,190,130$ & 0 & 1 & 0 & 0 & 1 & 2 & 0 & 2 \\
\hline 28 & $295,290,130,120$ & 0 & 0 & 0 & 0 & 2 & 2 & 0 & 2 \\
\hline 29 & $295,290,180,130,100$ & 0 & 1 & 0 & 0 & 0 & 1 & 0 & 1 \\
\hline 30 & $350,290,150,130$ & 0 & 0 & 1 & 0 & 0 & 1 & 0 & 1 \\
\hline 31 & $195,190,130,120,100$ & 0 & 0 & 0 & 0 & 1 & 1 & 0 & 1 \\
\hline 32 & $350,190,130,120$ & 0 & 0 & 0 & 0 & 1 & 1 & 0 & 1 \\
\hline 33 & $195,190,135,130$ & 0 & 0 & 0 & 0 & 1 & 1 & 0 & 1 \\
\hline 34 & $210,190,130,120,100$ & 0 & 0 & 0 & 0 & 1 & 1 & 0 & 1 \\
\hline Total & & 23 & 31 & 16 & 22 & 112 & 204 & 37 & 241 \\
\hline
\end{tabular}

* The lengths of DNA fragments are approximations.

and 17 genotypes consisted of 3 or fewer isolates (Table 1). Furthermore, 2 clones of the organisms, which were obtained from a single swab sample, were genetically different from one another (Table 2). These results suggest that the discrimination ability of the PCR-RFLP analysis was sufficiently strong to distinguish genital isolates of the organisms.

Between 1982 and 2004, no change was seen in the pattern of genotype distribution (Table 1). Between March, April, May and June of 2004, no noteworthy differences were detected (data not shown). These data suggested that $S$. zooepidemicus infection did not develop into an outbreak or prevalence according to
Table 2. Szp genotypes of 5 clones of $S$. zooepidemicus from each of 10 genital swabs taken from mares

\begin{tabular}{cc}
$\begin{array}{c}\text { Swab } \\
\text { no. }\end{array}$ & $\begin{array}{r}\text { Szp genotype(s) } \\
\text { (No. of isolates) }\end{array}$ \\
\hline 1 & $19(5)$ \\
2 & $7(5)$ \\
3 & $19(5)$ \\
4 & $1(5)$ \\
5 & $6(5)$ \\
6 & $5(4), 8(1)$ \\
7 & $1(5)$ \\
8 & $22(5)$ \\
9 & $3(5)$ \\
10 & $10(5)$ \\
\hline
\end{tabular}


specific genotypes, but is an infection in limited groups or an endogenous disease. Further investigation is needed to reveal the route of infection of $S$. zooepidemicus to the genitals.

As a result of this study, the major isolates were $s z p$ genotypes identified at both genital and respiratory sites, even though some genotypes were isolated from the genital site only or from the respiratory site only. Walker, R. L. et al. investigated the association of SzP protein variations in $S$. zooepidemicus with clinical manifestations of infection in horses, but no relationship was seen [9]. We have also previously reported that there were no differences in SzP types between isolates from healthy tonsils and isolates from lesions in pneumonia cases $[1,2]$. However, the SzP protein appears to be a pathogenic factor in $S$. zooepidemicus [10] and clearly has different types [this paper]. It is not clear if there is a relationship between $s z p$ genotypes and organotropism, in the same way as the relationships between the genotypes and pathogenicity are not clear. Further investigations are needed on this subject.

\section{References}

1. Anzai, T., Timoney, J.F., Kuwamoto, Y., Wada, R., Oikawa, M., and Higuchi, T. 2002. Polymerase chain reaction-restriction fragment length polymorphism analysis of the SzP gene of Streptococcus zooepidemicus isolated from the respiratory tract of horses. Am. J. Vet. Res. 63: 12981301.

2. Anzai, T., Walker, J., Blair, M.B., Chambers, T.M., and Timoney, J.F. 2000. Comparison of the phenotypes of Streptococcus zooepidemicus isolated from the tonsils of healthy horses and specimens obtained from foals and donkeys with pneumonia. Am. J. Vet. Res. 61: 162-166.

3. Hayakawa, Y., Komae, H., Ide, H., Nakagawa, H.,
Yoshida, Y., Kamada, M., Kataoka, Y., and Nakazawa, M. 1993. An occurrence of equine transport pneumonia caused by mixed infection with Pasteurella caballi, Streptococcus suis and Streptococcus zooepidemicus. J. Vet. Med. Sci. 55: 455456.

4. Hinrichs, K., Cummings, M.R., Sertich, P.L., and Kenney, R.M. 1998. Clinical significance of the aerobic bacterial flora of the uterus, vagina, vestibule, and clitoral fossa of clinically normal mares. J. Am. Vet. Med. Assoc. 193: 72-75.

5. Kamada, M., Oda, T., Wada, R., Fukunaga, Y., and Kumanomido, T. 1984. Isolation of Klebsiella pneumoniae, capsule type 1 , from mares with metritis and infertility in Japan. Bull. Equine Res. Inst. 21: 95-99.

6. Oikawa, M., Takagi, S., Anzai, T., Yoshikawa, H., and Yoshikawa, T. 1995. Pathology of equine respiratory disease occurring in association with transport. J. Comp. Path. 113: 29-43.

7. Timoney, J.F., and Mukhtar, M. 1993. Variability in the M-proteins of equine strains of Streptococcus equi subsp. zooepidemicus. pp.15-20. In: Equine Infectious Disease, Proceedings of the Sixth International Conference, Cambridge.

8. Timoney, J. F., Walker, J., Zhou, M., and Ding, J. 1995. Cloning and sequence analysis of a protective M-like protein gene from Streptococcus equi subsp. zooepidemicus. Infect. Immun. 63: 14401445 .

9. Walker, R.L., and Runyan, C.A. 2003. Identification of variations in SzP proteins of Streptococcus equi subspecies zooepidemicus and the relationship between protein variants and clinical signs of infection in horses. Am.J. Vet. Res. 64: 976981.

10. Walker, J.A., and Timoney, J.F. 1998. The molecular basis of variation in protective $\mathrm{SzP}$ proteins of Streptococcus zooepidemicus. Am. J. Vet. Res. 59: 1129-1133. 